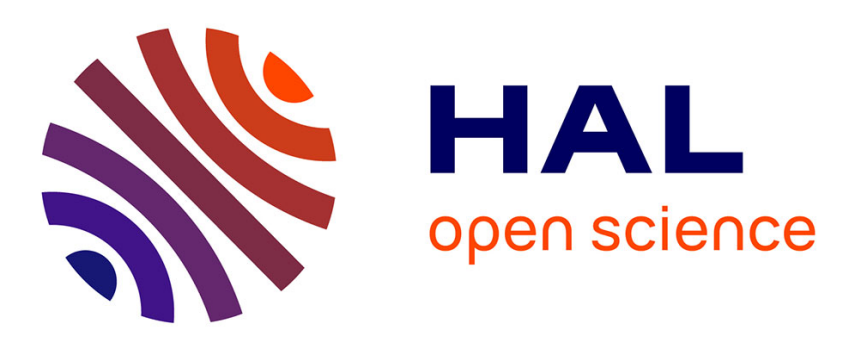

\title{
Influence of radiation-crosslinking on flame retarded polymer materials-How crosslinking disrupts the barrier effect
}

Rodolphe Sonnier, Anne-Sophie Caro-Bretelle, Loic Dumazert, Marc

Longerey, Belkacem Otazaghine

\section{To cite this version:}

Rodolphe Sonnier, Anne-Sophie Caro-Bretelle, Loic Dumazert, Marc Longerey, Belkacem Otazaghine. Influence of radiation-crosslinking on flame retarded polymer materials-How crosslinking disrupts the barrier effect. Radiation Physics and Chemistry, 2015, 106, pp.278-288. 10.1016/j.radphyschem.2014.08.012 . hal-02914238

\section{HAL Id: hal-02914238 \\ https://hal.science/hal-02914238}

Submitted on 25 May 2021

HAL is a multi-disciplinary open access archive for the deposit and dissemination of scientific research documents, whether they are published or not. The documents may come from teaching and research institutions in France or abroad, or from public or private research centers.
L'archive ouverte pluridisciplinaire HAL, est destinée au dépôt et à la diffusion de documents scientifiques de niveau recherche, publiés ou non, émanant des établissements d'enseignement et de recherche français ou étrangers, des laboratoires publics ou privés. 


\title{
Influence of radiation-crosslinking on flame retarded polymer materials-How crosslinking disrupts the barrier effect
}

\author{
Rodolphe Sonnier*, Anne-Sophie Caro-Bretelle, Loïc Dumazert, Marc Longerey, \\ Belkacem Otazaghine
}

Centre des Matériaux de l'Ecole des Mines d'Alès, 6, Avenue de Clavières, 30319 Alès Cedex, France

\section{H I G H L I G H T S}

- Polymers crosslinked by $\gamma$-irradiation undergo strong heat distortion during cone calorimeter test.

- Heat distortion is monitored by the high temperature gradient through the sample thickness.

- Flammability is variously influenced according to the mode-of-action of the flame retardant.

- When flame retardant acts through the formation of barrier layer, heat distortion breaks this layer.

- Barrier effect and flame retardancy are then deteriorated.

\begin{abstract}
A B S T R A C T
Fire behavior of flame retardant-free and flame retarded PP/PA6 blends was studied using pyrolysiscombustion flow calorimeter, cone calorimeter and epiradiator equipped with infrared camera and pyrometer. Blends were previously $\gamma$-irradiated in presence of crosslinking agents at various doses (up to $100 \mathrm{kGy}$ ) in order to assess the influence of irradiation crosslinking on flame retardancy. Crosslinked specimens exhibit a solid-like behavior under high temperature gradient in cone calorimeter and then distort considerably. The influence of such a behavior depends on the material properties. When the flame retardancy is provided by heat shielding effect, heat distortion disrupts the top protective layer leading to a substantial increase of peak of heat release rate (pHRR). The barrier layer is no longer able to prevent the heat transfer to the underlying condensed phase. In other cases (flame retardant-free blends or flame retardancy provided by other effects than heat shielding), heat distortion has negligible influence on heat release rate curves in cone calorimeter tests.
\end{abstract}

Keywords:

Flame retardancy

Barrier effect

Heat shielding

Heat distortion

\section{Introduction}

Gamma or electron beam irradiation has the potential to induce structural changes into a polymeric material. The net effect (chain scission, oxidation, crosslinking...) depends mainly on the polymer structure, the radiation dose and the atmosphere. Due to these changes, irradiation can influence significantly the fire behavior of a material. Some works have been dedicated to the role of irradiation on the flame retardancy. Elton (1998) increased the charring of a polyester fabric using electron beam irradiation in presence of divinylbenzene. Balabanovich et al. (1999, 2001, 2004; Balabanovich and Schnabel, 2002) have shown that

\footnotetext{
* Corresponding author.

E-mail address: rodolphe.sonnier@mines-ales.fr (R. Sonnier).
}

crosslinking by irradiation improves the flame retardancy of PA6, PA66 and PBT flame retarded with phosphorus additives.

But most articles concerned formulations used in the wire and cable industry. Indeed, polymers for insulating or jacketing materials in cables must be flame retarded. Poly(vinyl chloride) (Basfar, 2002, 2003; Salem et al., 2009) and especially polyolefins-based cables are quite often crosslinked by e-beam irradiation to improve their properties. Most generally, flame retardancy is measured via the measurement of the limiting oxygen index (LOI). Constant or slightly enhanced LOI is generally observed after irradiation of polymeric materials (Jia et al., 2003; Senna et al., 2012; Bee et al., 2013). Slightly better thermal stability and higher char content are also recognized as usual effects of irradiation (Jia et al., 2005). Hagiwara et al. have studied electric wires which jacket was irradiated polyethylene. They found that the flame retardancy is improved when the gel fraction increases up to a value of 60\% (Hagiwara et al., 1980). 
However contradictory results can be found in literature. Some works reported that irradiation can reduce the thermal stability, the char content or the LOI (Basfar, 2002; Jiao et al., 2006; Shukri et al., 2008; Wang et al., 2012; Seo et al., 2012), at least above a given radiation dose.

Few studies presented cone calorimeter data about irradiated flame retarded formulations (Jia et al., 2003, 2005; Lu et al., 2005, 2009; Coudreuse et al., 2010). Most of them showed that peak of heat release rate increases (i.e. the flame retardancy is negatively imparted, in contradiction with LOI measurements). However, once again, some exceptions can be found. For example, Jia et al. (2003) did not observe any change in pHRR of polyolefin-based materials after crosslinking by irradiation.

Indeed many phenomena can occur which would explain such apparent discrepancies. Chain scission competes with crosslinking and the presence of small molecules would promote ignition or decrease thermal stability. Dripping is prevented when the material is crosslinked and this can be detrimental in some tests (Balabanovich and Schnabel, 2002). Irradiation may modify the fillers (Shafiq and Yasin, 2012; Ahmad et al., 2013) and their dispersion into the matrix (Lu et al., 2005; Ismail et al., 2010; Ahmad et al., 2013; Zaidi et al., 2013) while dispersion is a key parameter controlling the flame retardancy. Crosslinking would prevent the expansion of intumescent systems and therefore their efficiency as flame retardants (Shukri et al., 2008). Interactions may be expected between the crosslinking additive and the flame retardant system (Shukri et al., 2008). If crosslinking exceeds a given level, cracks were observed on the outer layer of an electrical wire and the flame retardancy decreased (Hagiwara et al., 1980). The char of irradiated flame retarded polymers could be denser (Jia et al., 2003,2005 ) or more thermally stable (Balabanovich et al., 1999).

Moreover, interpretation of the results is quite often only suggested and not based on experimental evidences. The influence of most of the phenomena cited above has not been studied systematically. Therefore, investigations are still needed to understand how the structural changes induced by irradiation modify the fire behavior of polymers. In this article, we discuss the role of the heat distortion induced by the heat gradient into a radiationcrosslinked thermoplastic material on the flame retardancy.

\section{Materials and methods}

Homopolymer polypropylene is 505P from Sabic (density 0.905 ) and polyamide 6 is Technyl C206 Natural from Rhodia (density 1.14). The crosslinking agents 1,3,5-triallyl-1,3,5-triazinane-2,4,6-trione (TAIC-from Sigma Aldrich) and trimethylolpropane trimethacrylate (TMPTMA-from Sigma Aldrich) were used without any purification. Both additives are classically used for the crosslinking of PA6 (Pramanik et al., 2009) and PP (Lugao et al., 2007). Exolit OP1311 from Clariant is a non-halogenated flame retardant based on organic phosphinates. Nanofil 5 from Rockwood Additives Limited is an organically modified nanodispersible layered silicate based on a natural bentonite. The surface treatment is a dimethyl di(hydrogenated tallow)alkyl ammonium salt.

Compounds were prepared at $240{ }^{\circ} \mathrm{C}$ using a twin-screw extruder (Clextral BC21, $250 \mathrm{rpm}, 10 \mathrm{~kg} / \mathrm{h}$, screw length $900 \mathrm{~mm}$, L/D 36). PA6 was dried at $80{ }^{\circ} \mathrm{C}$ in air during at least $24 \mathrm{~h}$. Polymers and solid additives were mixed manually just prior to feeding the extruder. TAIC and TMPTMA were added manually in the melting zone. Extrudate was cooled in water and pelletized. Specimens $\left(100 \times 100 \times 4 \mathrm{~mm}^{3}\right)$ were injection molded at $240{ }^{\circ} \mathrm{C}$ using a $50 \mathrm{t}$ Krauss Maffei from the pellets, after vacuum drying at $80{ }^{\circ} \mathrm{C}$ for $12 \mathrm{~h}$. Mold temperature was set at $60^{\circ} \mathrm{C}$.

Non flame retarded and flame retarded blends are listed in Table 1. Irradiation of sheets was carried out by Ionisos SA (Dagneux, France), using a $2 \times 10^{6} \mathrm{Ci}^{60} \mathrm{Co}$ source, under air atmosphere and
Table 1

Studied PP/PA6 blends.

\begin{tabular}{lllllll}
\hline PP (phr) & $\begin{array}{l}\text { PA6 } \\
\text { (phr) }\end{array}$ & $\begin{array}{l}\text { TAIC } \\
\text { (phr) }\end{array}$ & $\begin{array}{l}\text { TMPTM- } \\
\text { A (phr) }\end{array}$ & $\begin{array}{l}\text { OP1311 } \\
\text { (phr) }\end{array}$ & $\begin{array}{l}\text { Nanofil } \\
\mathbf{5} \text { (phr) }\end{array}$ \\
\hline F1 & 79.5 & 20 & 0 & 0.5 & 0 & 0 \\
F2 & 80 & 19.5 & 0.5 & 0 & 0 & 0 \\
F3 & 79.5 & 19.5 & 0.5 & 0.5 & 0 & 0 \\
F4 & 79 & 20 & 0 & 1 & 0 & 0 \\
F5 & 80 & 19 & 1 & 0 & 0 & 0 \\
F5-1 & 80 & 19 & 1 & 0 & 7 & 0 \\
F5-2 & 80 & 19 & 1 & 0 & 15 & 0 \\
F5-3 & 80 & 19 & 1 & 0 & 0 & 3 \\
F5-4 & 80 & 19 & 1 & 0 & 12 & 3 \\
\hline
\end{tabular}

at ambient temperature. Irradiation dose was controlled with a precision of $5 \%$. Dose rate was $2 \mathrm{kGy} / \mathrm{h}$. Selected total doses were 20, 50 and $100 \mathrm{kGy}$.

Flammability was investigated using a pyrolysis combustion flow calorimeter (PCFC) which was developed by Lyon and Walters (2004). The sample $(2 \pm 0.5 \mathrm{mg})$ was first heated from 80 to $750{ }^{\circ} \mathrm{C}$ at $1{ }^{\circ} \mathrm{C} / \mathrm{s}$ in a pyrolyzer under nitrogen flow and the degradation products were sent to a combustor where they are mixed with oxygen in excess at $900{ }^{\circ} \mathrm{C}$. In such conditions, these products were fully oxidized. Heat release rate (HRR) was then calculated by oxygen depletion according to Huggett (1980)s relation (1 kg of consumed oxygen corresponds to $13.1 \mathrm{MJ}$ of released energy). Very small samples (several milligrams) could be analysed using PCFC. At such microscale, some flame retardant effects (as barrier effect) are not effective. Therefore fire behavior was also studied using a cone calorimeter (Fire Testing Technology) which is a powerful tool to investigate the fire behavior of polymers. A horizontal sample sheet of $100 \times 100 \times 4 \mathrm{~mm}^{3}$ was placed at $2.5 \mathrm{~cm}$ below a conic heater and isolated by rock wool. The samples were exposed to various irradiances in well-ventilated conditions (air rate $24 \mathrm{~L} / \mathrm{s}$ ) in the presence of a spark igniter to force the ignition. HRR was determined according to oxygen depletion (Huggett's relation) as in PCFC. This test was performed according to the ISO 5660 standard. Non flame retarded blends were tested several times at an irradiance of $50 \mathrm{~kW} / \mathrm{m}^{2}$. Each flame retarded blend was tested only once but at three irradiances $\left(35,50\right.$ and $\left.75 \mathrm{~kW} / \mathrm{m}^{2}\right)$. For F5 blend irradiated at $100 \mathrm{kGy}$, the temperature of the upper surface was measured during cone calorimeter test using an infrared camera (Optris). The distance between the specimen and the cone bottom was increased to $60 \mathrm{~mm}$ to allow a correct measurement but the heat flux was kept equal to $50 \mathrm{~kW} / \mathrm{m}^{2}$.

F5-4 blends were also characterized by infrared pyrometry coupled "epiradiator test" (French standard NFP 92-505). $70 \times 70 \times 4 \mathrm{~mm}^{3}$ specimens are exposed to a $500 \mathrm{~W}$ radiator (diameter $10 \mathrm{~cm}$, made of opaque quartz). Specimens are placed on a grid located $30 \mathrm{~mm}$ under the bottom of the epiradiator. The heat flux on the surface of the specimen was measured equal to $37 \mathrm{~kW} / \mathrm{m}^{2}$. Once the ignition occurs, the epiradiator is removed. The grid is pierced in its center. An infrared pyrometer (Optris CT) is placed perpendicularly to the surface below the specimen in order to measure the temperature of the lower surface through the grid hole. An infrared camera (Optris-temperature range $150-900{ }^{\circ} \mathrm{C}$ ) is placed in an inclined position above the specimen in order to record the temperatures field of the upper surface. The measured temperature with the infrared camera or the pyrometer depends not only on the surface temperature but also on the inclination of the apparatus relatively to the surface and the emissivity of the materials. Emissivity is chosen equal to 1 (close to the usual values for polymeric materials $0.8-0.9$ ). The inclination of the infrared camera is of few degrees relative to the perpendicular position, which limits the error on measurements. However the heat distortion 


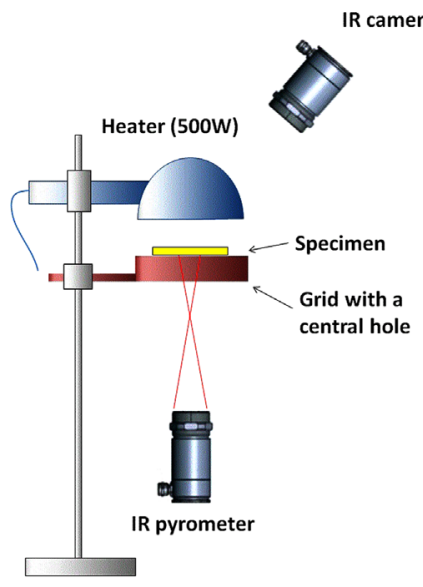

Before ignition

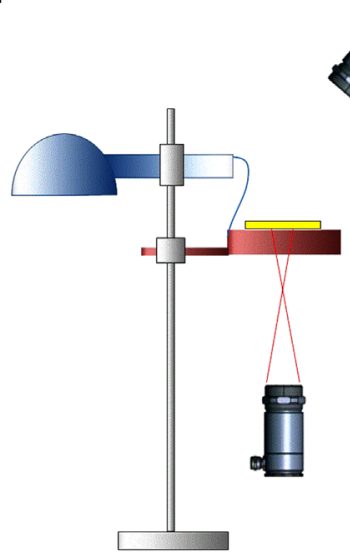

After ignition
Fig. 1. Scheme of epiradiator test equipped with IR camera and IR pyrometer.

of the specimen can modify this inclination during the test. As well, the flame can slightly disturb the measured temperatures. The infrared camera is calibrated to measure temperatures in the range 250-900 ${ }^{\circ} \mathrm{C}$. Therefore, the temperatures lower than $250^{\circ} \mathrm{C}$ are not measured. A scheme of the apparatus is shown in Fig. 1.

Young's modulus of the F5 blends was measured from 25 to $300{ }^{\circ} \mathrm{C}$ under air flow using dynamic thermomechanical analysis (DMA50, Metravib). A squared specimen (approximately $45 \times 10 \times 4 \mathrm{~mm}^{3}$ ) was held between two clamps and tension-compression sinusoidal cycles (frequency $5 \mathrm{~Hz}$ ) with deformation of $0.1 \%$ were applied. Heating rate was set at $7^{\circ} \mathrm{C} / \mathrm{min}$.

Linear dilation coefficients were measured from 25 to $300{ }^{\circ} \mathrm{C}$ under air flow using thermomechanical analysis (DMA50, Metravib). A squared specimen (approximately $20 \times 28 \times 4 \mathrm{~mm}^{3}$ ) was held between two plates and a small force $(1 \mathrm{~N})$ was continuously applied normally to the largest surface $\left(20 \times 28 \mathrm{~mm}^{2}\right)$. Heating rate was set at $7{ }^{\circ} \mathrm{C} / \mathrm{min}$. Variation in thickness was recorded to calculate linear dilation coefficients.

Density was measured at room temperature $\left(940 \mathrm{~kg} / \mathrm{m}^{3}\right)$ by weighting a specimen and measuring its dimensions. The value is close to that calculated from product datasheets using a linear rule of mixtures $\left(952 \mathrm{~kg} / \mathrm{m}^{3}\right)$. Density was calculated for higher temperatures (up to $300^{\circ} \mathrm{C}$ ) under air flow using thermomechanical analysis (DMA50, Metravib). A disc specimen (diameter $10 \mathrm{~mm}$, thickness $4 \mathrm{~mm}$ ) was positioned in a non-deformable cylinder (diameter $10 \mathrm{~mm}$ ). Therefore, change in sample size can occur only normally to the circular surface. A small force $(1 \mathrm{~N})$ was continuously applied using a piston (diameter $10 \mathrm{~mm}$ ) to measure change in specimen thickness. Considering negligible weight loss (less than $3 \%$ at $300{ }^{\circ} \mathrm{C}$ ), density can be calculated.

Specific heat in kJ/g.K of the F5 blend irradiated at $100 \mathrm{kGy}$ was measured using a Perkin Elmer differential scanning calorimetry (Stepscan software). Measurements were carried out at various temperatures up to $300{ }^{\circ} \mathrm{C}$. Specific heat in $\mathrm{kJ} / \mathrm{m}^{3}$.K was calculated using density values obtained as described above.

Thermal diffusivity $D\left(\mathrm{~m}^{2} / \mathrm{s}\right)$ of the $\mathrm{F} 5$ blend irradiated at 100 kGy was measured using a Laser Flash apparatus (XFA600 from Linseis). The specimen was stamped from an injection-molded $100 \times 100 \times 4 \mathrm{~mm}^{3}$ sheet, thinned to a thickness of $2 \mathrm{~mm}$ and coated with graphite on both surfaces. Measurements were carried out at various temperatures up to $300{ }^{\circ} \mathrm{C}$ in helium. The thermal conductivity $\lambda(\mathrm{W} / \mathrm{m} \mathrm{K})$ is calculated from thermal diffusivity, specific heat $c(\mathrm{~J} / \mathrm{kg} \mathrm{K})$ and density $\rho\left(\mathrm{kg} / \mathrm{m}^{3}\right)$ according to Eq. (1):

$\lambda=D \times \rho \times c$

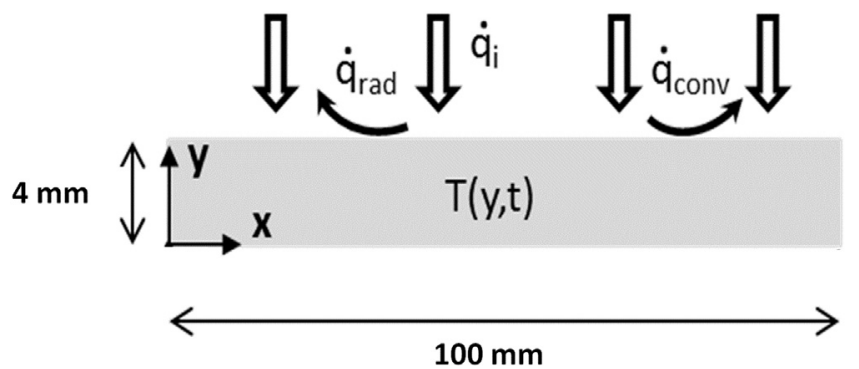

Fig. 2. Finite elements simulation: initial sample geometry and boundaries conditions (out of plane dimension equal to $100 \mathrm{~mm}$ ).

Thermal conductivity at $300{ }^{\circ} \mathrm{C}$ was calculated by extrapolation, because the specimen is not stiff enough to remain positioned in the sample holder.

A cone calorimeter test simulation, incorporating the mechanical/thermal blend behavior and the radiation/convection boundaries conditions, was performed. The heating process was described up to a few seconds beyond ignition (weight loss by polymer ablation is neglected) and the coupling effect between time evolutive material properties (both thermal and mechanical) was enhanced. The model implementation did not use a direct coupling of thermal and mechanical processes but rather employed the evaluated temperature fields as input for the mechanical constitutive model in a weak coupling formulation. At each step of the calculation, a temperature map was first obtained through the sample; then this temperature was used for the mechanical computation through the mechanical model to evaluate stress/strain sample cartography. The accuracy of the model was demonstrated through a comparison between model predictions and experimental measurements. The sample geometry is a $100 \times 100 \times 4 \mathrm{~mm}^{3}$ parallelogram. Its upper surface was exposed to an incident radiative heat flux $\left(\dot{q}_{i}\right)$ and exhibited heat losses by convection and radiation ( $\dot{q}_{\text {conv }}$ and $\dot{q}_{\text {rad }}-$ see Fig. 2 ). The sample was embedded inside an aluminum foil, all the other sides of the sample were not supposed to transfer any flux, the test was therefore restrained by these thermal conditions thus mandating a 3D numerical simulation. The finite element simulation needed a body discretization defined by nodal points. Temperature, displacement, stress or strain were therefore defined at each nodal point (coordinates $(x, y, z)$ ) and each time of simulation $(t)$.

The sample thermal equilibrium equation is given by Eq. (2) on the temperature which depends only on $y$ variable (homogeneous material).

$\rho(t) c(t) \frac{\partial T(y, t)}{\partial t}=\lambda(t) \frac{\partial^{2} T(y, t)}{\partial y^{2}}$

where $\rho(t), c(t)$ and $\lambda(t)$ are the density, the specific heat and the thermal conductivity, respectively.

By considering the incident heat flux and the losses due to convection and radiation, the heat flux given at time $t$ on the sample surface is

$-\lambda(t) \frac{\partial T}{\partial y}(4, t)=\dot{q}^{\prime \prime}{ }_{i}(t)-a\left(T^{4}-T_{e}^{4}\right)-h_{c}\left(T-T_{e}\right)$

where $a$ is the product of the Stefan-Boltzmann constant $\left(5.73 \times 10^{-8} \mathrm{~W} / \mathrm{m}^{2} \mathrm{~K}^{4}\right)$ by the surface emissivity value, $T_{e}$ is the reference temperature and $h_{c}\left(\mathrm{~W} / \mathrm{m}^{2} \mathrm{~K}\right)$ is a constant parameter.

The sample lower surface is assumed to be insulated, as well as all the other faces except the upper surface.

$-\lambda(t) \frac{\partial T}{\partial y}(0, t)=0$ 
The static mechanical governing equation is

$\operatorname{div} \sigma(x, y, z, t)=0$

where $\sigma$ is the Cauchy stress tensor.

As the considered material is assumed to be linear, homogeneous and isotropic, the Cauchy stress tensor $\sigma$ is related to the strain deformation tensor $\varepsilon$ by the relation:

$\sigma_{i j}(x, y, z, t)=A_{i j k l}(x, y, z, t) \varepsilon_{k l}(x, y, z, t)+L_{i j}(x, y, z, t)\left(T(y, t)-T_{0}\right)$

with

$A_{i j k l}(x, y, z, t)=\frac{E(x, y, z, t)}{2(1+\nu)}\left(\delta_{i l} \delta_{j k}+\delta_{i k} \delta_{j l}\right)+\frac{2 \nu}{1-2 \nu} \delta_{i j} \delta_{k l}$

$L_{i j}(x, y, z, t)=-\frac{E(x, y, z, t) \alpha(x, y, z, t)}{1-2 \nu} \delta_{i j}$

where $\alpha(x, y, z, t)$, the linear expansion coefficient, is evaluated at each computation time $t$ and $\delta_{i j}$ is the Kronecker tensor component. In this last expression, the Young's modulus $E$ depends on both time and spatiality (as the temperature increases) although the Poisson's ratio is assumed to be constant for sake of simplicity. The boundary conditions on the displacement vector $\vec{u}$ for the mechanical problem is (the bottom corner is fixed in translation)

$\vec{u}(0,0, z)=\vec{u}(100,0, z)=\overrightarrow{0} \quad \forall z \in[0,100]$

A finite element mesh was generated with 2800 quadratic elements and 4428 nodal points with the computer code ZeBuLON ${ }^{\circledR}$ (Paris School of Mines, Paris, France, Besson, 1998).

\section{Results and discussion}

Non flame retarded and flame retarded blends were studied successively. Finally the fire behavior of the F5-4 blend (exhibiting the most efficient barrier effect when it was not irradiated) was examined using additional experiments.

\subsection{Fire behavior of FR-free PP/PA6}

PCFC analyses show similar results for all blends. Heat Release Rate curves are presented in Fig. 3 for the unirradiated and irradiated F5 blends. The temperature of the pHRR is not significantly modified by $\gamma$-irradiation and remains in the range $465-477^{\circ} \mathrm{C}$ whichever the radiation dose. Total Heat Release is constant at $38.5( \pm 2) \mathrm{kJ} / \mathrm{g}$, in good agreement with the value calculated according a linear rule of mixtures. However, pHRR values decrease continuously with the radiation dose. This significant decrease is close to $25 \%$ when radiation dose reaches $100 \mathrm{kGy}$. The same behavior was observed for F1, F2, F3 and F4 samples (data not shown).

The same results were also observed for all the flame retarded polymers studied in the second part of this study (decrease in pHRR and no significant change in THR and peak temperature, data not shown).

Heat release rate curves measured in cone calorimeter tests are also very similar for all blends whichever the radiation dose and the crosslinking agent. pHRR is close to $1000 \mathrm{~kW} / \mathrm{m}^{2}$ (never lower than $850 \mathrm{~kW} / \mathrm{m}^{2}$ ). Time-to-ignition and THR are in the range $28-34 \mathrm{~s}$ and $150-160 \mathrm{MJ} / \mathrm{m}^{2}$, respectively. A plateau more or less pronounced is observed few seconds after ignition and followed by a fast increase up to the pHRR. HRR decreases quickly after this point. Such curves are typical for thick non charring material (Schartel and Hull, 2007). Indeed, none of the blends showed any char residue. As an example, Fig. 4 shows the HRR curves for the unirradiated and irradiated F5 blends.

Nevertheless, although the cone calorimeter data are the same for all blends, strong differences were observed about the

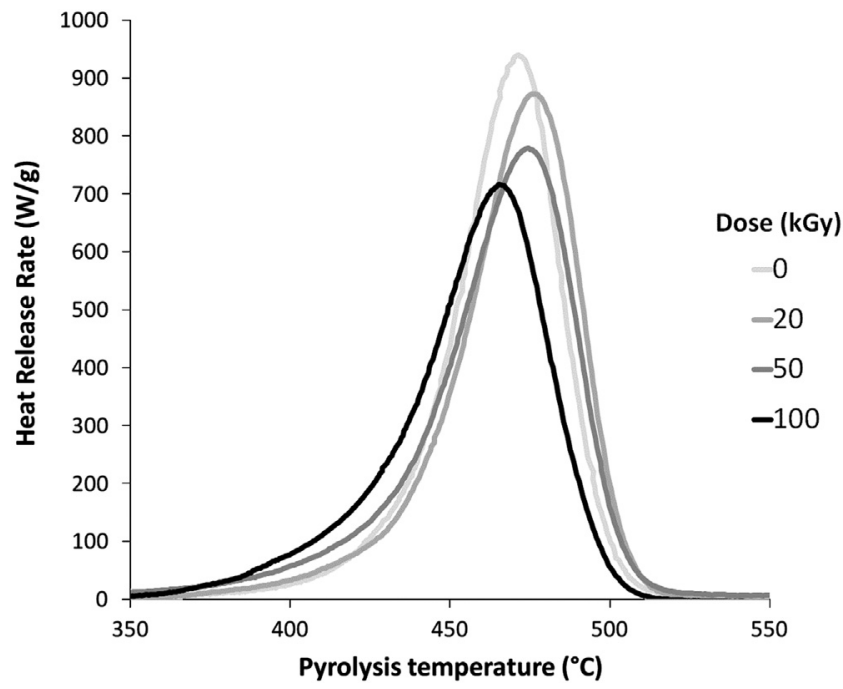

Fig. 3. HRR $(\mathrm{W} / \mathrm{g})$ versus temperature obtained by PCFC analyses with a heating rate of $\beta=1{ }^{\circ} \mathrm{C} / \mathrm{s}$ under nitrogen atmosphere for $\mathrm{F} 5$ blends irradiated at various doses.

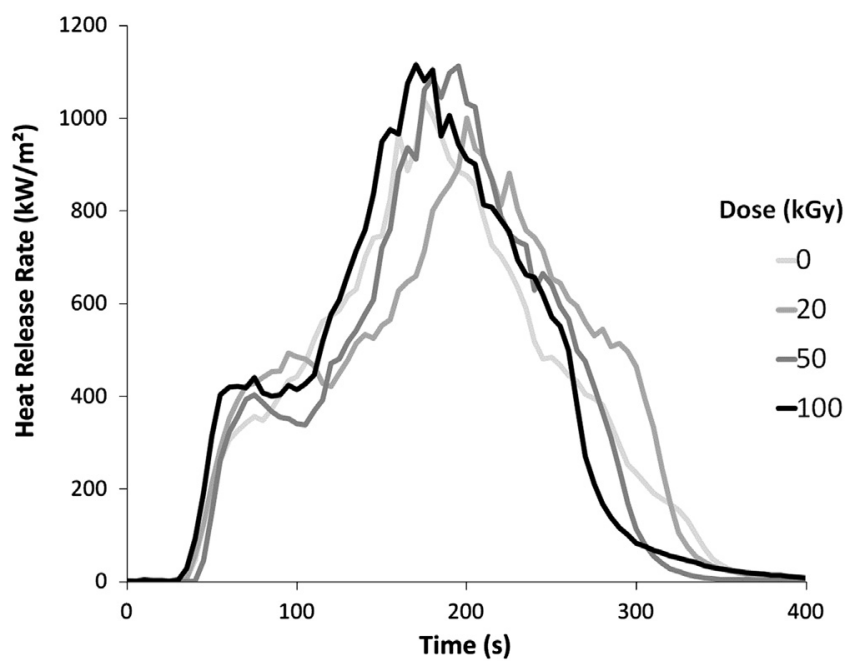

Fig. 4. HRR $\left(\mathrm{kW} / \mathrm{m}^{2}\right)$ versus time obtained using cone calorimeter with an irradiance of $50 \mathrm{~kW} / \mathrm{m}^{2}$ for F5 blends.

macroscopic behavior of the specimens. Some specimens exhibited a significant heat distortion after ignition. Heat distortion was not observed for unirradiated blends but appeared for irradiated blends, which are partially crosslinked. Higher was the radiation dose, greater was the distortion of the specimens. Moreover, the phenomenon was dependent on the additive used and its content: TAIC was clearly more efficient to promote the crosslinking which is responsible for heat distortion. Pramanik et al. have shown that no gel formation is observed in PA6 with TMPTMA when the radiation dose does not exceed $100 \mathrm{kGy}$. On the contrary, high gel fraction can be achieved in presence of TAIC even at low radiation dose (25 kGy) (Pramanik et al., 2009). Similarly, TAIC allows reaching higher gel fraction in PP than TMPTMA with a radiation dose of $20 \mathrm{kGy}$ (Lugao et al., 2007).

Fig. 5 depicts some examples of heat distortion observed during the cone calorimeter tests. The distortion can be limited in height and in area (local distortion-Fig. 5a), moderate but overall (Fig. 5b) or strong and overall (Fig. 5c). The latter case was observed only for F5 blends irradiated at 50 and $100 \mathrm{kGy}$, and corresponds to higher crosslinking. While the objective of this work is to study the influence of the heat distortion on the flame 

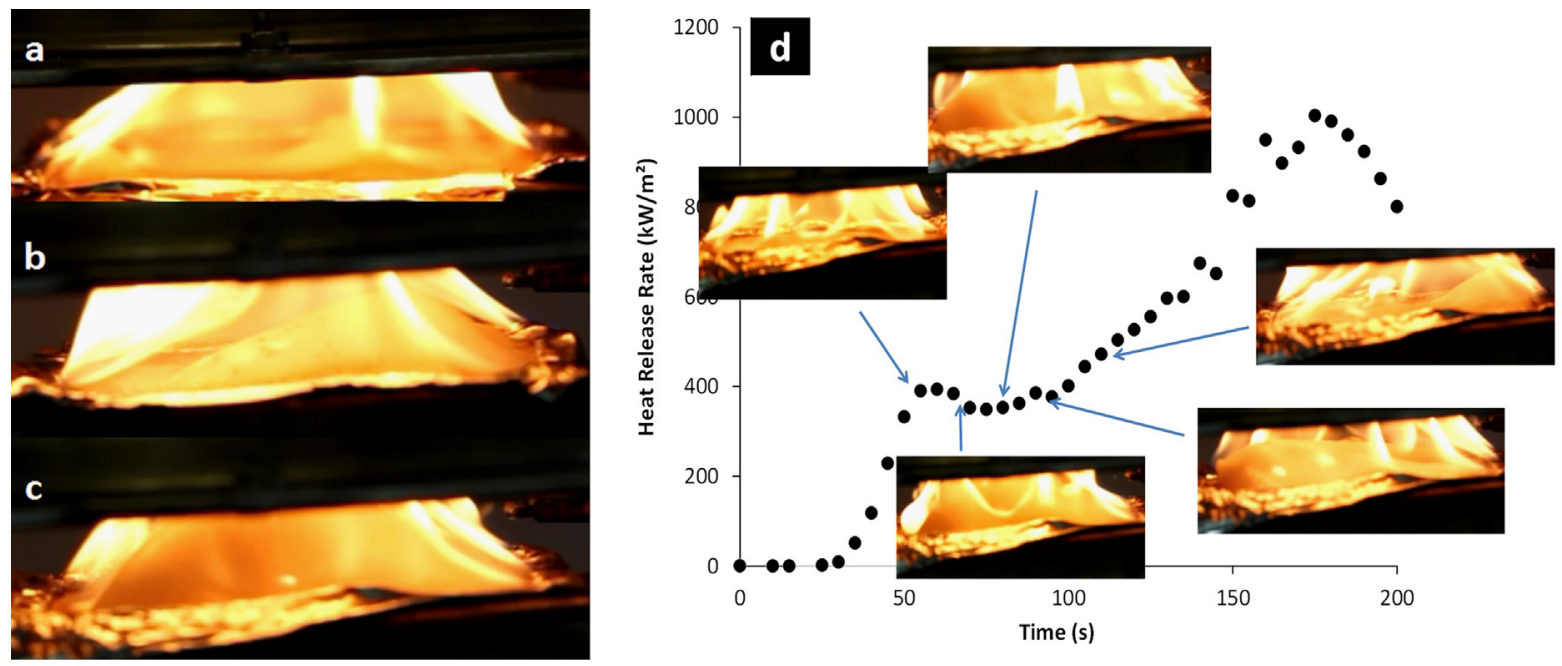

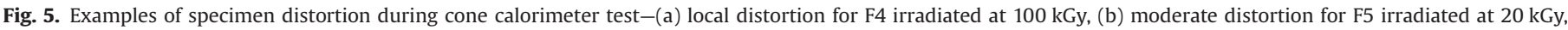

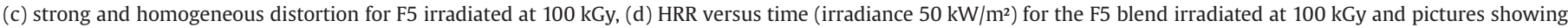
heat distortion.

retardancy, this blend (containing $1 \mathrm{phr}$ of TAIC) was selected for the preparation of flame retarded blends (F5-1 to F5-4).

Fig. 5d shows the HRR curve for the F5 blend irradiated at $100 \mathrm{kGy}$ and some pictures of the distortion of the specimen at different times during the test. Distortion starts few seconds after ignition and the specimen collapses before reaching the pHRR. In fact distortion and collapse occur during the HRR plateau. Nevertheless, such a plateau is observed for all blends. Therefore, it is assumed that heat distortion does not affect the HRR curve for FR-free blends.

It must be noticed that crosslinking density was not measured in this study. Indeed, crosslinking can happen in various extents not only in both phases (PP and PA6) but also at the interface (interfacial crosslinking). Therefore, it is quite difficult to quantitatively assess the crosslinking density of our materials, even when they are unfilled. To overcome this issue, dynamic thermomechanical analysis was carried out. It is well known that the modulus at the rubbery plateau (i.e. higher than melting temperature for semi-crystalline polymers) is a clear indication of the crosslinking density.

Thermomechanical properties of F5 blends are shown in Fig. 6. Young's modulus $E$ is similar for all blends at room temperature whichever the radiation dose and decreases slowly when the temperature increases. Above $150{ }^{\circ} \mathrm{C}$, the decrease is faster and corresponds to PP melting. The curves differ beyond this step. Unirradiated F5 blend is not crosslinked and $E$ drops off due to the specimen collapse. For F5 blend irradiated at $20 \mathrm{kGy}, E$ decreases due to the PA6 melting up to a rubbery plateau evidencing the crosslinking of the material. For F5 blends irradiated at 50 and $100 \mathrm{kGy}$, a first plateau is observed between the PP and PA6 melting steps and the Young's modulus at the rubbery plateau is higher than for a radiation dose of $20 \mathrm{kGy}$. The rubbery plateau is quite stable despite the degradation of the material (formation of a thin black layer on the surface, which is typical of PA6 thermooxidation). The Young's modulus at the rubbery plateau is in good agreement with the heat distortion observed during cone calorimeter tests: Heat distortion is not observed for unirradiated F5 blend, moderate for F5 blend irradiated at $20 \mathrm{kGy}$ and stronger for F5 blends irradiated at higher doses (50 and $100 \mathrm{kGy}$ ).

An attempt to model the macroscopic behavior (i.e. heat distortion) of F5 blend irradiated at $100 \mathrm{kGy}$ is carried out using some thermophysical and thermomechanical properties of the material. In order to fit correctly the behavior of the blend, a set of

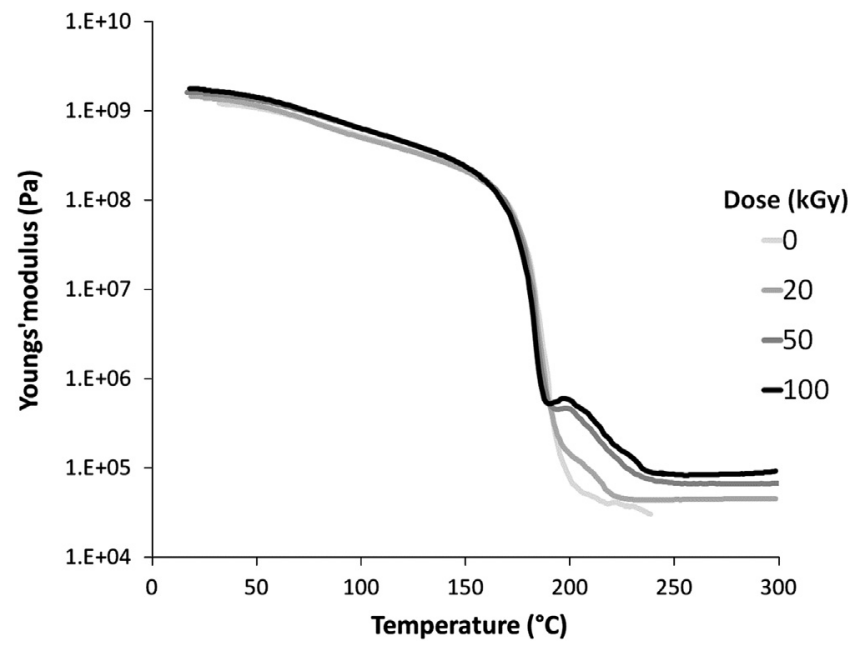

Fig. 6. Young's modulus $E$ ( $\mathrm{Pa}$ ) versus temperature for $\mathrm{F} 5$ blends.

influent material properties is measured at room and high temperatures following the protocols described in Section 2. Nevertheless measurements are carried out up to $300{ }^{\circ} \mathrm{C}$ while the temperature of the condensed phase reaches $400-500{ }^{\circ} \mathrm{C}$ (see below). At higher temperatures, values are kept constant or extrapolated. DMA and TMA measurements (for the calculation of Young's modulus, density and linear coefficients of dilation) are carried out in air atmosphere while specific heat and thermal diffusivity are measured in nitrogen atmosphere. Nevertheless in all cases, weight loss is very limited (less than 3\% in air). Poisson's ratio is set at 0.3 and the reference temperature is $T_{e}=25^{\circ} \mathrm{C}$. Despite these limitations, the simulation with these input data gives a goo insight of the heat distortion.

A numerical simulation has been performed on the F5 blend irradiated at $100 \mathrm{kGy}$ to model the macroscopic behavior. To run this simulation the needed parameters are

- for the thermal resolution: (a) the boundaries conditions on the upper surface are the incident heat flux which is fitted and applied to obtain the suitable top surface temperature evolution (measured using IR camera) and the heat loss by radiation and convection (respective coefficients are done in Table 2) and 
(b) the material thermal properties (conductivity and the specific heat evolutions (see Table 2),

- for the mechanical resolution: (a) the boundaries conditions (the displacements) and (b) the material mechanical properties (Young's modulus, Poisson's ratio and secant dilation coefficient evolution). This last parameter has been evaluated from the linear dilation coefficients through the formula:

$\alpha_{C}(t)=\frac{1}{T(t)-T_{e}} \int_{T_{e}}^{T(t)} \alpha(t) d t$

The values are all listed in Table 3.

Tables 2 and 3 show the material properties for the temperatures reached at various times on the upper surface. Obviously, due to the high temperature gradient, all the material properties also exhibit significant gradients through the specimen thickness. Therefore these properties correspond only to those of the upper surface.

Irradiance changes during the cone calorimeter test. Before ignition, the applied irradiance (incident flux) is $50 \mathrm{~kW} / \mathrm{m}^{2}$. After ignition, incident flux on the surface depends not only on the applied irradiance, but also on the heat from flame. Schartel and Weib (2010) have considered a value of $30 \mathrm{~kW} / \mathrm{m}^{2}$ for the heat flux from the flame. Net heat flux is lower than incident flux due to loss by radiation and convection (see Eq. (3)). The temperature of the upper surface at ignition is chosen equal to $723 \mathrm{~K}\left(450{ }^{\circ} \mathrm{C}\right.$ - in good agreement with IR camera measurements - see Fig. 7). For the simulation, the heat flux is chosen to fit the upper surface temperature. It can be observed that the heat flux is close to $50 \mathrm{~kW} / \mathrm{m}^{2}$ before ignition (between 4 and $27 \mathrm{~s}$ ) and increases after ignition ( $128 \mathrm{~kW} / \mathrm{m}^{2}$ few seconds after).

At each time of the simulation and for each point of the sample, the heat transfer and its mechanical impact can be described through the sample. The first results confirm the sample distortion exhibited during the process: we observe a non-linear displacement of the central point (up to $10 \mathrm{~mm}$ ) with a faster increase just after the ignition (see Fig. 7). This observation is a direct consequence of the variation of dilation as a function of temperature: two nodal points showing different temperatures will lead to contraction due to the strain gradient. This evolution is qualitatively in agreement with the experimental observations. Nevertheless, the modelled distortion is quite lower than the experimental one. One of the main reasons is that the corners of the specimen are fixed in the simulation while these corners can move (and actually move) horizontally during the cone calorimeter test.

This numerical modelling gives also useful information on stress evolution. Since the test is multiaxial, we look after the equivalent stress which is

$\sigma_{e q}(t)=\sqrt{\frac{3}{2} \sum_{i j} \sigma_{i j} \sigma_{j i}-\frac{1}{2}\left(\sum_{k} \sigma_{k k}\right)^{2}}$

The observed stress concentration (red areas in Fig. 8) could explain the localisation of cracks observed after the ignition for the flame retarded blend F5-4 (see below).

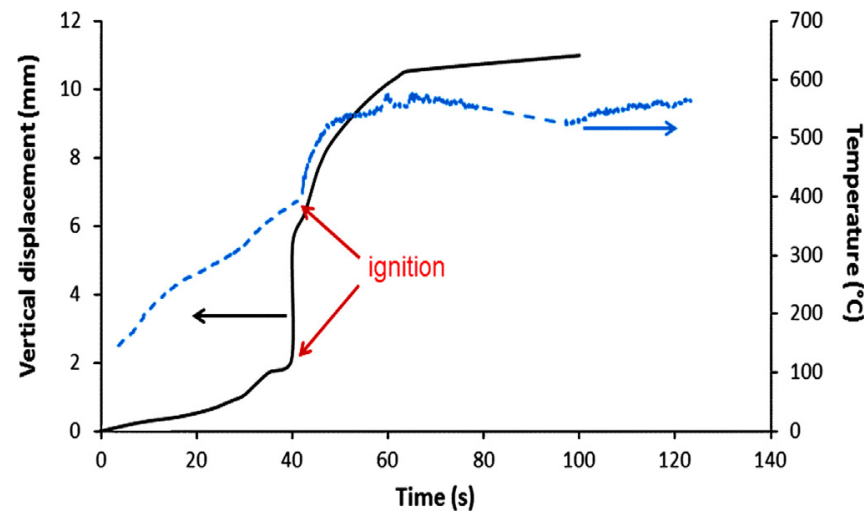

Fig. 7. Numerical displacement of the central point (coordinates $(50 \mathrm{~mm}, 4 \mathrm{~mm}, 50 \mathrm{~mm})$ ) and experimental temperature vs time for F5 blend.

Table 2

Material thermal properties for the finite element modelling (*these parameters are not measured but assumed).

\begin{tabular}{|c|c|c|c|c|c|c|c|}
\hline \multirow[t]{2}{*}{ Time $(\mathrm{s})$} & \multicolumn{4}{|c|}{ Material thermal properties } & \multicolumn{3}{|c|}{ Boundary thermal conditions (upper surface) } \\
\hline & Temperature (K) & $\begin{array}{l}\text { Thermal conductivity } \\
(\mathrm{W} / \mathrm{m} \mathrm{K})\end{array}$ & $\begin{array}{l}\text { Density } \\
\left(\mathrm{kg} / \mathrm{m}^{3}\right)\end{array}$ & $\begin{array}{l}\text { Specific heat } \\
\left(\mathrm{kJ} / \mathrm{m}^{3} \mathrm{~K}\right)\end{array}$ & $\begin{array}{l}\text { Incident flux } \\
\left(\mathrm{kW} / \mathrm{m}^{2}\right)\end{array}$ & $\begin{array}{l}\text { Radiation } a \\
\left(\mathrm{~W} / \mathrm{m}^{2} \mathrm{~K}^{4}\right)\end{array}$ & $\begin{array}{l}\text { Convection } h_{c} \\
\left(\mathrm{~W} / \mathrm{m}^{2} \mathrm{~K}\right)\end{array}$ \\
\hline 0 & 298 & 0.508 & 940 & 1993 & 108 & $5.73 \times 10^{-8}$ & 10 \\
\hline 4 & 373 & 0.677 & 937 & 2670 & 52 & $5.73 \times 10^{-8}$ & 10 \\
\hline 9 & 473 & 0.823 & 924 & 3483 & 70 & $5.73 \times 10^{-8}$ & 10 \\
\hline 27 & 573 & $1.017^{*}$ & 615 & 2399 & 52 & $5.73 \times 10^{-8}$ & 10 \\
\hline 42 & 673 (ignition) & 1.200 & $615^{*}$ & $2399^{*}$ & 70 & $5.73 \times 10^{-8}$ & 10 \\
\hline 45 & 773 & 1.383 & $615^{*}$ & $2399^{*}$ & 128 & $5.73 \times 10^{-8}$ & 10 \\
\hline 70 & 840 & 1.383 & $615^{*}$ & $2399^{*}$ & 35 & $5.73 \times 10^{-8}$ & 10 \\
\hline 100 & 840 & 1.383 & $615^{*}$ & $2399^{*}$ & 35 & $5.73 \times 10^{-8}$ & 10 \\
\hline
\end{tabular}

Table 3

Material mechanical properties for the finite element modelling ( ${ }^{*}$ these parameters are not measured but assumed).

\begin{tabular}{|c|c|c|c|c|c|c|}
\hline \multicolumn{6}{|c|}{ Material mechanical properties } & \multirow{2}{*}{$\begin{array}{l}\text { Boundary mechanical conditions } \\
\text { Displacements (bottom corners) (Mm) }\end{array}$} \\
\hline Time (s) & Temperature (K) & $\begin{array}{l}\text { Young's modulus } \\
E(\mathrm{MPa})\end{array}$ & Poisson's ratio & $\begin{array}{l}\text { Dilation coefficient } \\
\alpha\left(\mathrm{K}^{-1}\right)\end{array}$ & $\begin{array}{l}\text { Secant dilation coefficient } \\
\alpha_{C}\left(\mathrm{~K}^{-1}\right)\end{array}$ & \\
\hline 0 & 298 & 1730 & 0.3 & $1.1 \times 10^{-5}$ & $6.2 \times 10^{-6}$ & 0 \\
\hline 4 & 373 & 631 & 0.3 & $1.3 \times 10^{-5}$ & $5.1 \times 10^{-6}$ & 0 \\
\hline 9 & 473 & 0.6 & 0.3 & $2.7 \times 10^{-5}$ & $7.1 \times 10^{-6}$ & 0 \\
\hline 27 & 573 & 0.09 & 0.3 & $2.2 \times 10^{-4}$ & $2.4 \times 10^{-5}$ & 0 \\
\hline 42 & 673 (ignition) & $0.09 *$ & 0.3 & $2.2 \times 10^{-4 *}$ & $2.4 \times 10^{-5 *}$ & 0 \\
\hline 45 & 773 & $0.09^{*}$ & 0.3 & $2.5 \times 10^{-4 *}$ & $1.4 \times 10^{-4 *}$ & 0 \\
\hline 70 & 840 & $0.09^{*}$ & 0.3 & $2.5 \times 10^{-4 *}$ & $1.4 \times 10^{-4 *}$ & 0 \\
\hline 100 & 840 & $0.09^{*}$ & 0.3 & $2.5 \times 10^{-4 *}$ & $1.4 \times 10^{-4 *}$ & 0 \\
\hline
\end{tabular}




\subsection{Fire behavior of flame retarded PP/PA6}

Four flame retardant systems were incorporated into the F5 PP/ PA6 blend containing TAIC. The formulations (F5-1 to F5-4) are listed in Table 1. The objective of this work is to ascertain the influence of the heat distortion (due to the crosslinking rate) on the flame retardancy. Therefore, the optimization of the flame retardancy effect of these FR systems is out of the scope. However, the choice of these flame retardant systems can be justified in few words. Phosphorusbased FRs are well known to promote charring of some polymers (as PA6). The char can allow preventing the heat and gas transfers between the flame and the condensed phase. Additionally some phosphorus-based FRs can also act in gaseous phase as radical scavengers. A content of 7phr of OP1311 (F5-1) is probably not high enough to improve significantly the flame retardancy but $15 \mathrm{phr}$ (F52) should decrease the flammability of the material. Nanoclays (F5-3) can also reduce very efficiently the pHRR in cone calorimeter even at very low content (1-3 wt\%) if the clays are well dispersed (Samyn et al., 2008). Finally, the combination of phosphorus-based FRs and nanoclays (F5-4) was extensively studied and some works reported efficient synergism when the FR system was not intumescent (Quach et al., 2012).

Fig. 9 shows the heat release rate of the unirradiated flame retarded blends versus time in cone calorimeter test at an irradiance of $35 \mathrm{~kW} / \mathrm{m}^{2}$. Table 4 summarizes the results. All the formulations lead to a decrease in pHRR in comparison to the pure

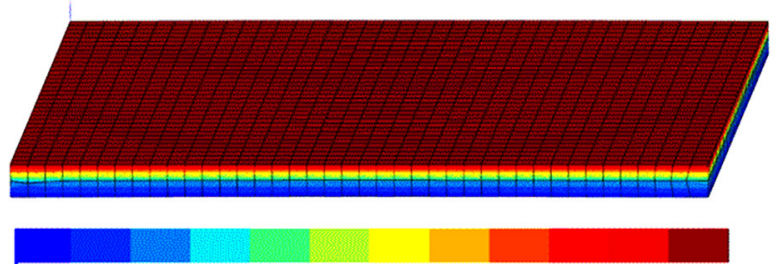

304 Temperature map $\left({ }^{\circ} \mathrm{K}\right)$

481
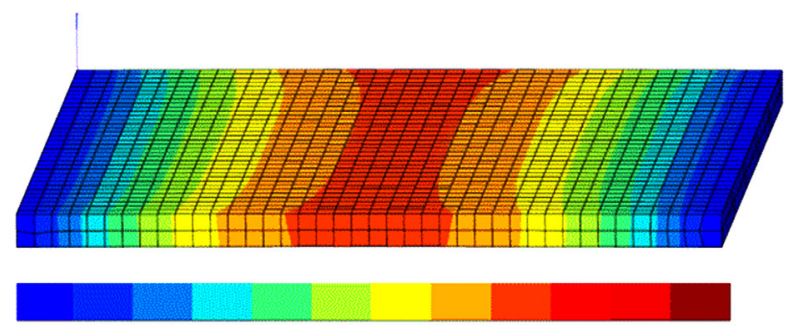

O Normal displacement $(\mathrm{mm})$

0,4

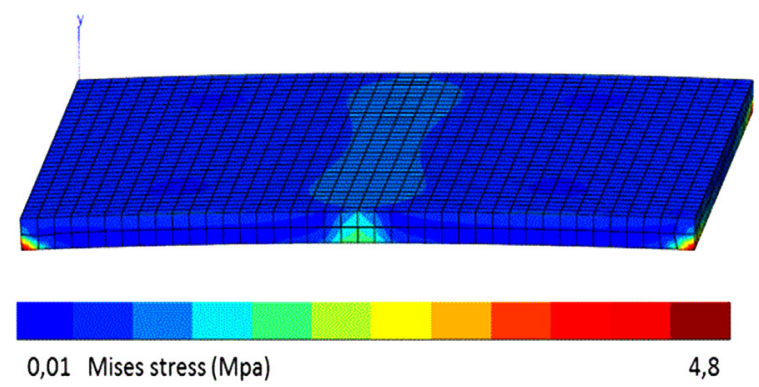

Before the ignition ( $t=10 \mathrm{~s}$ )
F5 blend (compare Fig. 4 and data at $50 \mathrm{~kW} / \mathrm{m}^{2}$ in Table 4). Significant differences can be observed. Time-to-ignition is higher for F5-3 blends. F5-1, F5-2 and F5-4 blends exhibit a lower Effective Heat of Combustion (EHC) than F5-3 blend. Therefore,

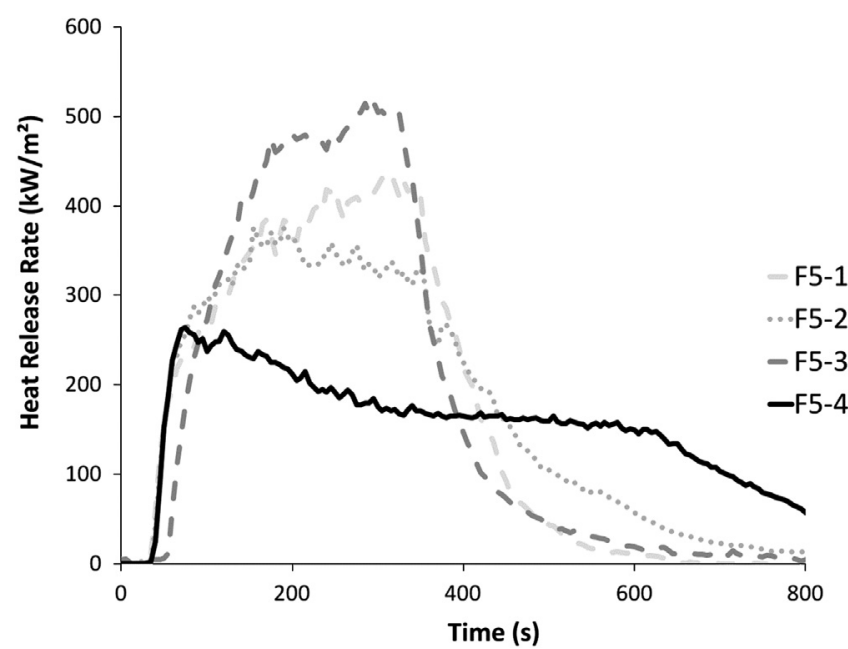

Fig. 9. HRR $\left(\mathrm{kW} / \mathrm{m}^{2}\right)$ versus time obtained by cone calorimeter analyses with an irradiance of $35 \mathrm{~kW} / \mathrm{m}^{2}$ for unirradiated flame retarded $\mathrm{F} 5$ blends.

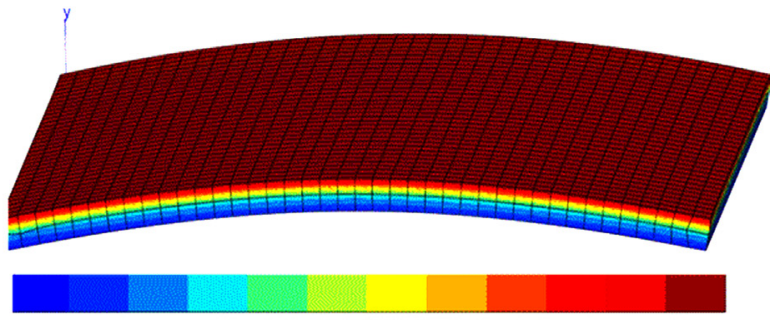

533 Temperature map ( $\left.{ }^{\circ} \mathrm{K}\right)$ 710
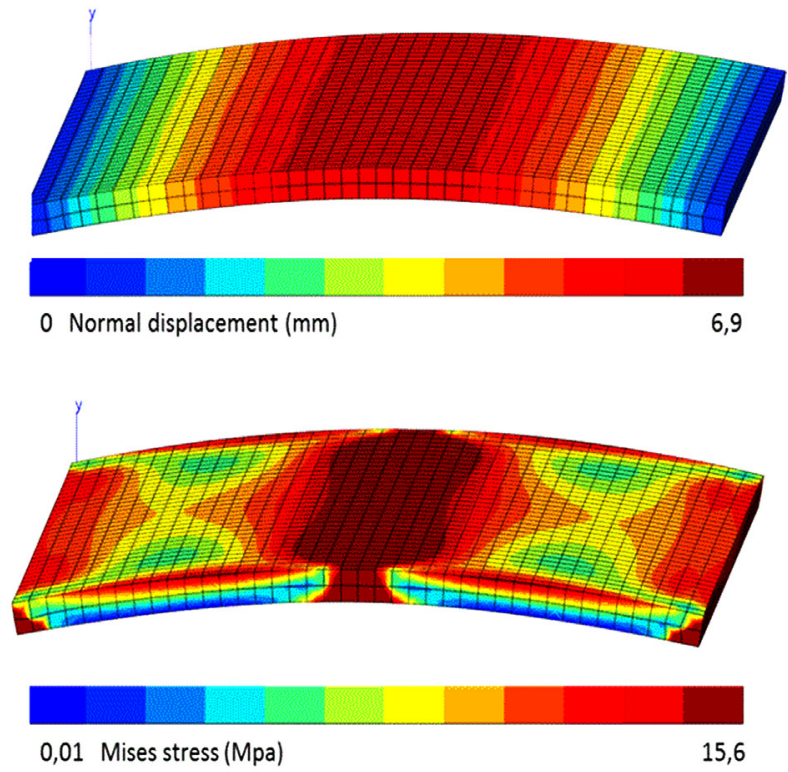

After the ignition $(t=42,5 s)$

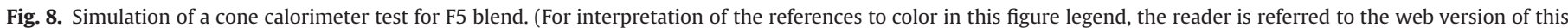
article.) 


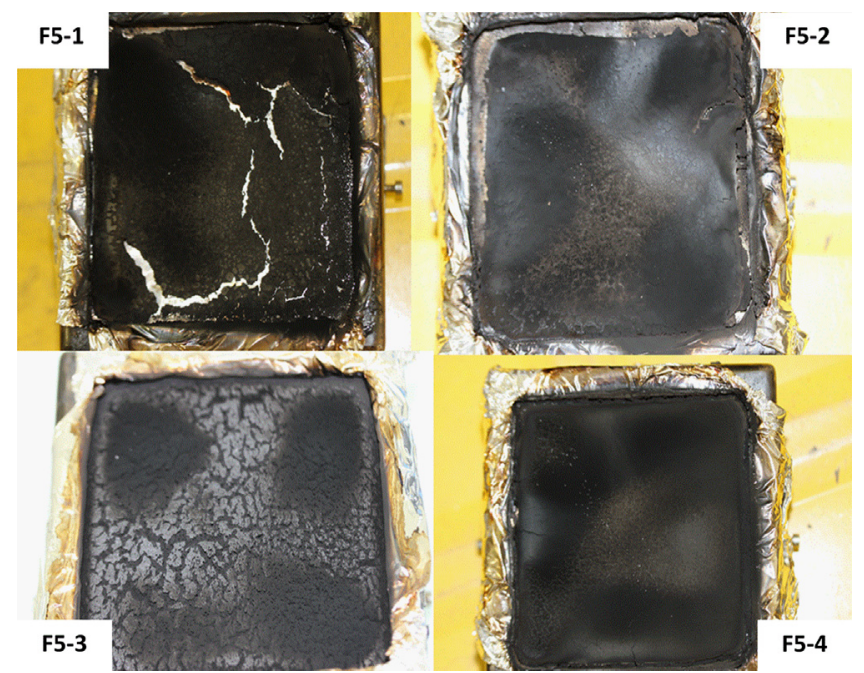

Fig. 10. Residues of the four unirradiated blends after cone calorimeter tests at $35 \mathrm{~kW} / \mathrm{m}^{2}$.

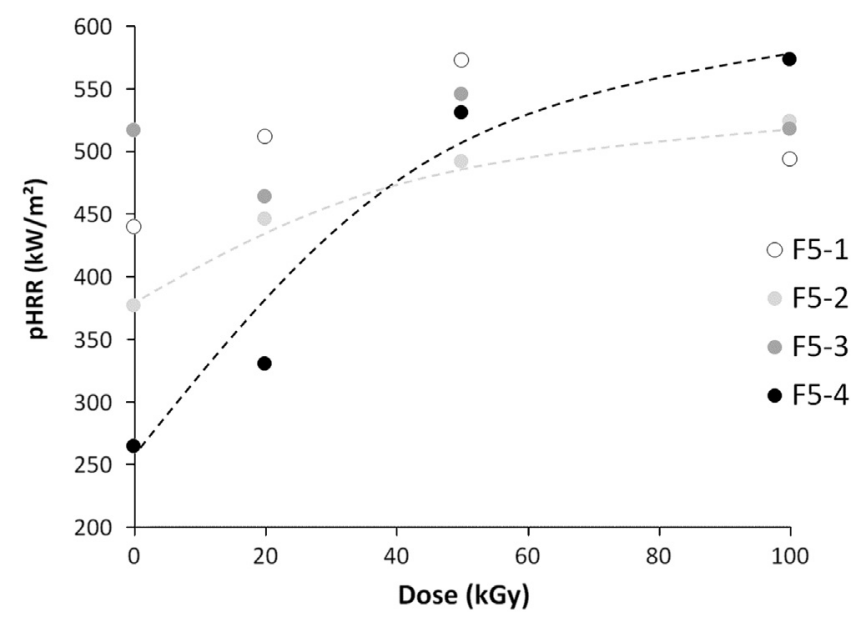

Fig. 11. Peak of heat release rate versus radiation dose for flame retarded F5 blends at an irradiance of $35 \mathrm{~kW} / \mathrm{m}^{2}$.

phosphorus FR can be assumed to act partially by flame inhibition or by dilution of fuels (due to the release of gases having low EHC).

F5-1 and F5-3 exhibit a high pHRR (in the range $430-520 \mathrm{~kW} / \mathrm{m}^{2}$ ). Moreover the HRR increases continuously and decreases quickly only when the fuel begins to fail (the weight loss at pHRR is in the range $67-72 \%)$.

On the contrary, F5-4 exhibits a low pHRR shortly after ignition (around $260 \mathrm{~kW} / \mathrm{m}^{2}$ corresponding to a mass loss less than $6 \mathrm{wt} \%$, $35 \mathrm{~s}$ after ignition), followed by a slow decrease. The shape of the HRR curve is typical of an efficient barrier effect (thick charring behavior according to Schartel and Hull, 2007) due to the formation of a char which prevents the heat transfer from the flame to the condensed phase and the fuel transfer from the condensed phase to the flame.

The behavior of F5-2 is intermediate with a higher pHRR $\left(376 \mathrm{~kW} / \mathrm{m}^{2}\right)$ than $\mathrm{F} 5-4$ followed by a slightly decreasing pseudoplateau and finally a faster decrease after $350 \mathrm{~s}$. This is indicative of a rather ineffective barrier effect.

Residues can be observed in Fig. 10 for the four blends. For F5-1 and $\mathrm{F} 5-3$, the residues exhibit some cracks. The residue is particularly thin in the case of F5-1. In the contrary F5-2 and F5-4 exhibit a more cohesive and thicker surface (particularly for F5-4). Residue yields (see Table 4) are also very low for F5-1 and F5-3 (1.3 and $2.3 w t \%$, respectively). Such a residue yield is probably not
Table 4

Cone calorimeter data for flame retarded PP/PA6 blends.

\begin{tabular}{|c|c|c|c|c|c|c|c|}
\hline Blend & $\begin{array}{l}\text { Radiation } \\
\text { dose (kGy) }\end{array}$ & $\begin{array}{l}\text { Irradiance } \\
\left(\mathbf{k W} / \mathbf{m}^{2}\right)\end{array}$ & $\begin{array}{l}\text { TTI } \\
(\mathbf{s})\end{array}$ & $\begin{array}{l}\text { pHRR } \\
\left(\mathrm{kW} / \mathrm{m}^{2}\right)\end{array}$ & $\begin{array}{l}\text { THR } \\
\left(\mathrm{MJ} / \mathrm{m}^{2}\right)\end{array}$ & $\begin{array}{l}\text { Residue } \\
\text { (wt\%) }\end{array}$ & $\begin{array}{l}\text { EHC } \\
(\mathrm{kJ} / \mathrm{g})\end{array}$ \\
\hline \multirow[t]{12}{*}{ F5-1 } & 0 & 35 & 32 & 439 & 136 & 1.3 & 35.3 \\
\hline & 0 & 50 & 22 & 714 & 139 & 1.3 & 35.9 \\
\hline & 0 & 75 & 10 & 891 & 134 & 0.2 & 34.6 \\
\hline & 20 & 35 & 31 & 511 & 138 & 1.6 & 36.1 \\
\hline & 20 & 50 & 19 & 723 & 140 & 2.3 & 35.8 \\
\hline & 20 & 75 & 9 & 1128 & 138 & 0 & 35.6 \\
\hline & 50 & 35 & 37 & 572 & 141 & 2.0 & 36.9 \\
\hline & 50 & 50 & 21 & 763 & 142 & 1.1 & 36.9 \\
\hline & 50 & 75 & 9 & 1010 & 136 & 0 & 34.9 \\
\hline & 100 & 35 & 37 & 493 & 139 & 2.0 & 36.7 \\
\hline & 100 & 50 & 25 & 749 & 142 & 0.6 & 37.3 \\
\hline & 100 & 75 & 12 & 1287 & 143 & 0 & 36.7 \\
\hline \multirow[t]{12}{*}{ F5-2 } & 0 & 35 & 34 & 376 & 142 & 3.1 & 37.0 \\
\hline & 0 & 50 & 23 & 477 & 135 & 1.4 & 34.5 \\
\hline & 0 & 75 & 10 & 662 & 131 & 2.8 & 34.0 \\
\hline & 20 & 35 & 35 & 445 & 139 & 4.2 & 36.3 \\
\hline & 20 & 50 & 22 & 587 & 133 & 3.1 & 34.1 \\
\hline & 20 & 75 & 10 & 848 & 135 & 2.2 & 34.6 \\
\hline & 50 & 35 & 33 & 491 & 142 & 3.6 & 37.2 \\
\hline & 50 & 50 & 20 & 624 & 135 & 2.2 & 34.6 \\
\hline & 50 & 75 & 9 & 931 & 136 & 2.2 & 34.8 \\
\hline & 100 & 35 & 37 & 523 & 149 & 3.5 & 39.1 \\
\hline & 100 & 50 & 25 & 627 & 140 & 1.4 & 35.6 \\
\hline & 100 & 75 & 9 & 910 & 136 & 2.5 & 34.8 \\
\hline \multirow[t]{12}{*}{ F5-3 } & 0 & 35 & 51 & 516 & 145 & 2.3 & 38.8 \\
\hline & 0 & 50 & 27 & 765 & 151 & 1.8 & 39.8 \\
\hline & 0 & 75 & 14 & 979 & 149 & 0 & 38.9 \\
\hline & 20 & 35 & 53 & 463 & 146 & 2.3 & 38.9 \\
\hline & 20 & 50 & 26 & 706 & 151 & 1.7 & 40.0 \\
\hline & 20 & 75 & 14 & 934 & 150 & 0.5 & 39.4 \\
\hline & 50 & 35 & 49 & 545 & 147 & 2.5 & 39.2 \\
\hline & 50 & 50 & 27 & 680 & 152 & 2.1 & 40.6 \\
\hline & 50 & 75 & 14 & 1030 & 151 & 1.1 & 39.7 \\
\hline & 100 & 35 & 49 & 517 & 149 & 1.4 & 39.4 \\
\hline & 100 & 50 & 27 & 729 & 154 & 1.5 & 41.1 \\
\hline & 100 & 75 & 13 & 1095 & 152 & 1.7 & 40.0 \\
\hline \multirow[t]{12}{*}{ F5-4 } & 0 & 35 & 40 & 264 & 134 & 6.2 & 35.8 \\
\hline & 0 & 50 & 22 & 360 & 139 & 4.9 & 37.5 \\
\hline & 0 & 75 & 11 & 505 & 135 & 4.8 & 35.6 \\
\hline & 20 & 35 & 35 & 330 & 141 & 7.0 & 37.8 \\
\hline & 20 & 50 & 24 & 593 & 136 & 5.2 & 36.0 \\
\hline & 20 & 75 & 10 & 628 & 137 & 4.6 & 36.0 \\
\hline & 50 & 35 & 34 & 530 & 141 & 6.7 & 37.5 \\
\hline & 50 & 50 & 22 & 625 & 138 & 5.7 & 36.7 \\
\hline & 50 & 75 & 11 & 591 & 138 & 4.8 & 36.2 \\
\hline & 100 & 35 & 35 & 573 & 140 & 6.5 & 37.5 \\
\hline & 100 & 50 & 21 & 661 & 137 & 4.5 & 35.8 \\
\hline & 100 & 75 & 10 & 784 & 140 & 5.1 & 36.9 \\
\hline
\end{tabular}

high enough to ensure a perfect covering of the surface. F5-2 and especially F5-4 exhibit a higher residue yield (3.1 and $6.2 \mathrm{wt} \%$ ).

All these observations are in good agreement with the efficiency of the barrier effect as deduced from the heat release rate curves.

It should be noted that none of the unirradiated flame retarded blends showed any distortion during the test. On the contrary, all the irradiated blends underwent significant heat distortion (as the FR-free F5 blend) after gamma irradiation, particularly at high radiation dose (50 and $100 \mathrm{kGy}$ ).

While all irradiated blends underwent heat distortion, the change in heat release rate curves is very different. Nevertheless, for a given blend, similar results can be drawn for the three irradiances. For F5-1 and F5-3, the evolution of pHRR is not significant. Considering the uncertainties, pHRR can be assumed constant whichever the radiation dose (for F5-1, at $35 \mathrm{~kW} / \mathrm{m}^{2}$, the pHRR increases when the radiation dose increases from 0 to $50 \mathrm{kGy}$ but this change is not confirmed at higher irradiance). 


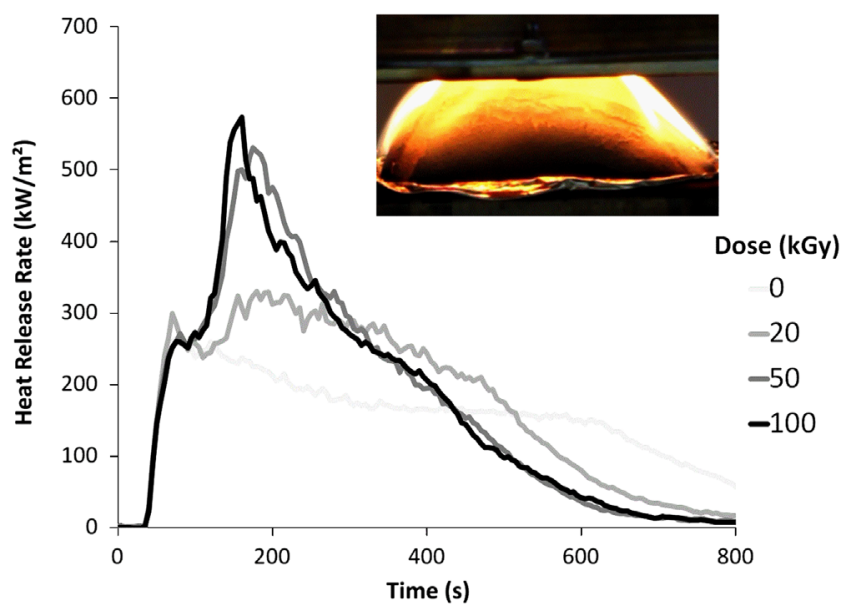

Fig. 12. HRR $\left(\mathrm{kW} / \mathrm{m}^{2}\right)$ versus time obtained by cone calorimeter analyses with an irradiance of $35 \mathrm{~kW} / \mathrm{m}^{2}$ for flame retarded F5-4 blends-the picture shows the heat distortion of F5-4 blend irradiated at $100 \mathrm{kGy}$ (at $101 \mathrm{~s}$ ).

For F5-4, the pHRR increases strongly when the radiation dose increases from 0 to $50 \mathrm{kGy}$ (Fig. 11). A further but more limited increase is observed from 50 to $100 \mathrm{kGy}$. At an irradiance of $35 \mathrm{~kW} / \mathrm{m}^{2}$, the pHRR increases from $264 \mathrm{~kW} / \mathrm{m}^{2}$ (for unirradiated F5-4) to $573 \mathrm{~kW} / \mathrm{m}^{2}$ (for F5-4 blend irradiated at $100 \mathrm{kGy}$ ), i.e. the best unirradiated flame retarded blend becomes the worst one after irradiation at high dose.

For F5-2, the pHRR also increases with radiation dose but the increase is more limited (from 376 to $523 \mathrm{~kW} / \mathrm{m}^{2}$ when radiation dose increases from 0 to $100 \mathrm{kGy}$ ).

These results can be related to the main mode-of-action of the FR systems as discussed above. For F5-1 and F5-3, barrier effect is inefficient and the pHRR does not change whichever the radiation dose. For F5-2, the barrier effect is moderate and the pHRR increases with dose radiation. For F5-4, the barrier effect is much efficient before irradiation and the increase in pHRR after irradiation is the highest of the four blends.

Unirradiated and irradiated F5 blends were studied in cone calorimeter tests using higher irradiances (50 and $75 \mathrm{~kW} / \mathrm{m}^{2}$ ). Table 4 summarizes the main data extracted from these experiments. Time-to-ignition decreases and pHRR increases when the applied irradiance increases. Effective heat of combustion is not modified. Residue generally decreases, probably because the thermo-oxidation of the formed char at the end of the test increases with the irradiance. Therefore THR should be slightly higher but the variation is in the uncertainty range. The evolution of pHRR with the radiation dose discussed above for an irradiance of $35 \mathrm{~kW} / \mathrm{m}^{2}$ is confirmed at higher irradiances for all blends. In particular, for F5-4 blend, the pHRR increases with the radiation dose whichever the irradiance (see Fig. S1 in supporting information).

\subsection{Fire behavior of F5-4 blends}

In the following F5-4 blends were studied in detail and using additional experiments to point out the breakdown of the barrier layer due to heat distortion. Heat release rate curves of the four F5-4 blends in cone calorimeter test at an irradiance of $35 \mathrm{~kW} / \mathrm{m}^{2}$ are shown in Fig. 12. It is obvious that the shape of the curve completely changes with irradiation. While the unirradiated blend exhibits the typical shape of a thick charring behavior (low pHRR followed by a slow decrease of HRR), at high radiation dose, a sharp pHRR is observed followed by a faster decrease. Strong heat distortion occurs (see picture) then the specimen collapses.

Residues of F5-4 blends after cone calorimeter tests at $35 \mathrm{~kW} / \mathrm{m}^{2}$ are shown in Fig. 13. The surface of the residue is cohesive and

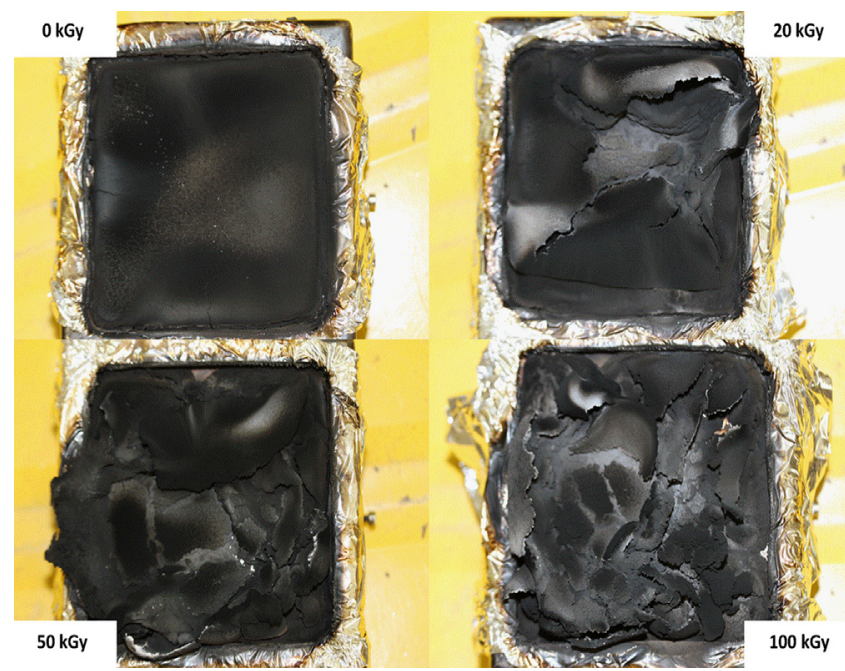

Fig. 13. Residues of the F5-4 blends after cone calorimeter tests at $35 \mathrm{~kW} / \mathrm{m}^{2}$.

smooth when the blend was not irradiated. After irradiation, top layer was broken. Higher the radiation dose was, more cracks were observed. At $20 \mathrm{kGy}$, residue surface layer was broken into few large parts. At $100 \mathrm{kGy}$, surface layer was broken into many small parts. This is due to the distortion of the specimen followed by its collapse. These observations are fully in agreement with the removal of the barrier effect.

The blends were ignited using epiradiator test. Pictures of the upper surface were recorded using the IR camera (Fig. 14 and Figs. S2-S4 in supporting information). In all cases, the charring starts early and a char layer is already formed few seconds after ignition. In the case of the unirradiated F5-4 blend (Fig. S2 in supporting information), the sheet is not distorted during the test but the burning area decreases slowly up to flame out (after $17 \mathrm{~min}$ ). It is the reason why the area having a temperature greater than $150{ }^{\circ} \mathrm{C}$ decreases.

For F5-4 blend irradiated at $20 \mathrm{kGy}$ (Fig. S3 in supporting information), the sheet begins to be distorted few seconds after ignition. The sheet expands and collapses (after $300 \mathrm{~s}$ ), leading to a char layer partially disrupted. Nevertheless, the charring continues and a protective layer is formed again. Therefore, the flammability is controlled and the burning area decreases.

The distortion is more severe for the F5-4 blends irradiated at $50 \mathrm{kGy}$ and $100 \mathrm{kGy}$. For the former (Fig. S4 in supporting information), cracks are clearly visible after $200 \mathrm{~s}$. After $300 \mathrm{~s}$, a hole is formed in the centre due to the falling material through the central hole of the grid. The evolution of the temperature profile of the upper surface is similar for the F5-4 blend irradiated at 100 kGy (Fig. 14). Distortion occurs fast and cracks are also visible (from $187 \mathrm{~s}$ to $292 \mathrm{~s}$ in Fig. 14). A hole is also formed after $350 \mathrm{~s}$ (picture at $394 \mathrm{~s}$ ).

It is quite difficult to give an accurate temperature of the burning upper surface because of the heat distortion of the specimen (for irradiated blends) and the slow decrease of the burning area (for the unirradiated blend). The temperature of the upper surface is in the range $400-500{ }^{\circ} \mathrm{C}$ after ignition for the four blends (data not shown). This range corresponds quite well to the temperatures range of material pyrolysis as measured using PCFC $\left(400-500^{\circ} \mathrm{C}\right)$.

Temperatures of the lower surface are shown in Fig. 15 for unirradiated and irradiated F5-4 blends. The temperature increase is similar for the four blends up to ignition (at 150-180 s). After ignition, the temperature for the unirradiated F5-4 blend increases very slowly. The char layer is forming on the upper surface and the pyrolysis front does not move through the thickness. The burning area decreases and flame out occurs after more than $1000 \mathrm{~s}$. The 


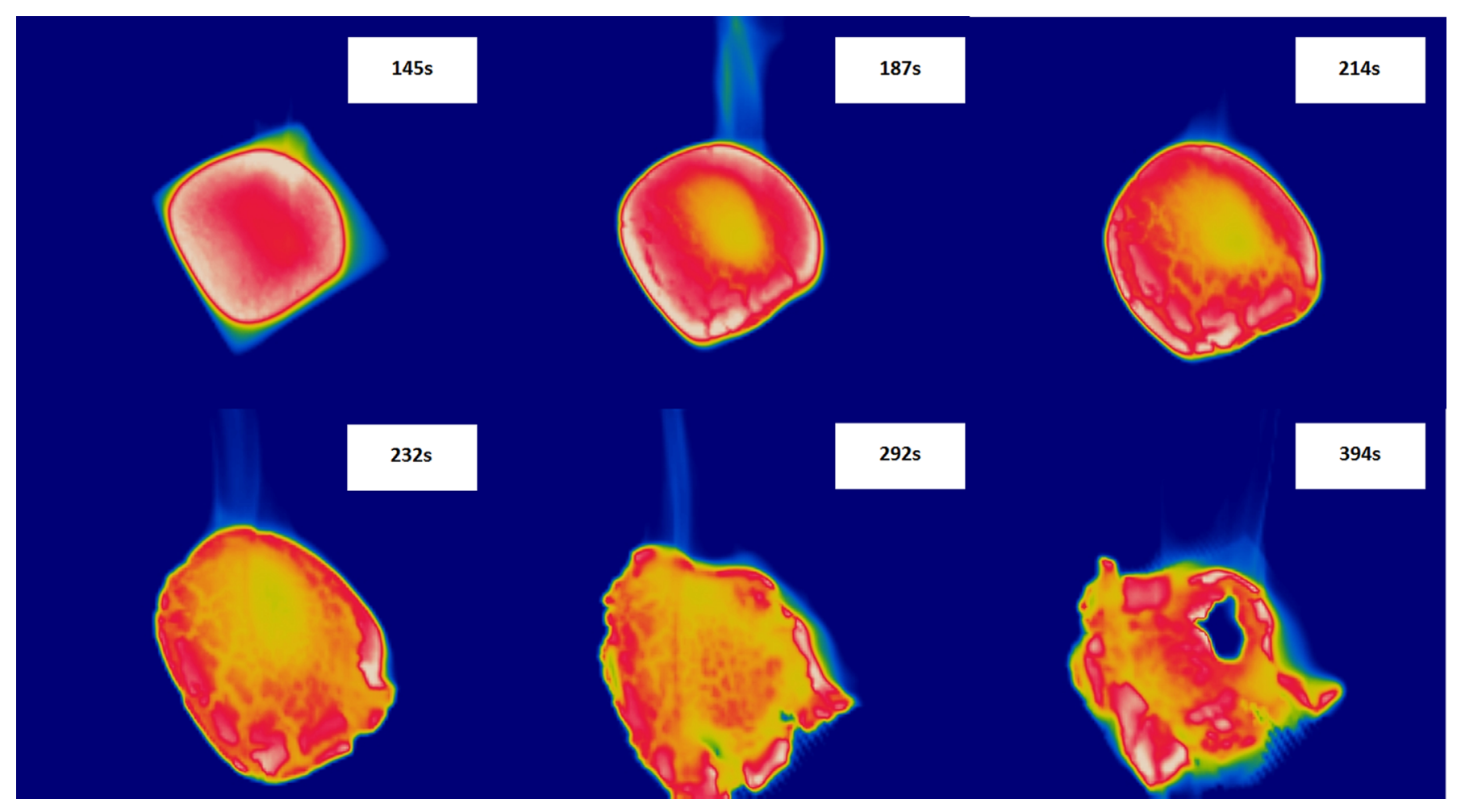

Fig. 14. Temperatures field of the upper surface for F5-4 blend irradiated at $100 \mathrm{kGy}$ during epiradiator test.

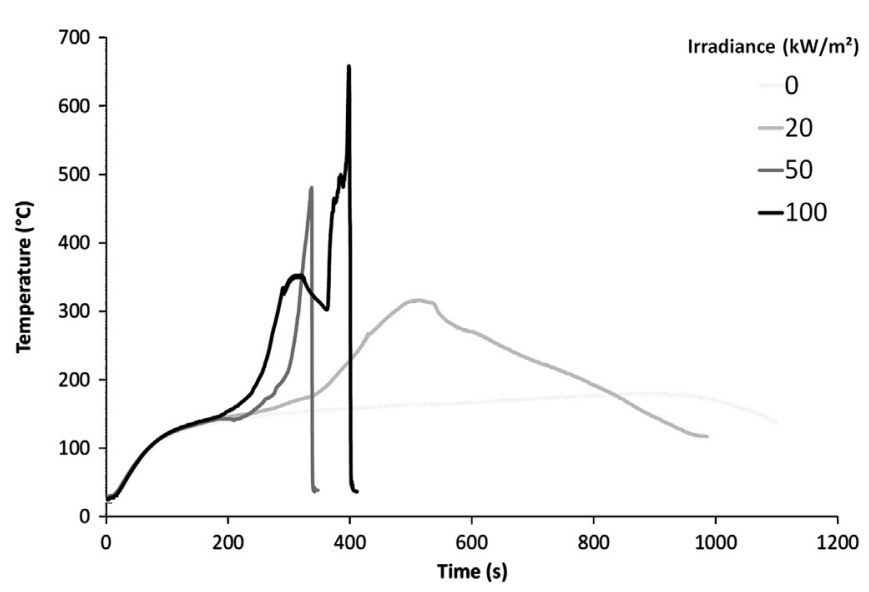

Fig. 15. Temperature of the lower surface for F5-4 blends during epiradiator test.

temperature of the lower surface decreases few seconds before because the heat transfer is not high enough (the flame becomes very small). During the whole test, the temperature of the lower surface does not reach $200{ }^{\circ} \mathrm{C}$. This is a clear evidence of the barrier effect of the char layer on the upper surface.

For F5-4 blend irradiated at a moderate dose (20 kGy), the temperature of the lower surface increases faster after ignition and particularly after $350 \mathrm{~s}$. The temperature raises up to $300{ }^{\circ} \mathrm{C}$. This increase corresponds well to the heat distortion of the sheet which leads to the breakdown of the char protective layer. Nevertheless, the material just below this layer degrades and generates additional charring. Therefore, a protective layer is formed again and prevents efficiently the heat transfer. Then the temperature of the lower surface drops down (after $500 \mathrm{~s}$ ) and the burning area is reducing up to flame out.

For F5-4 blends irradiated at higher dose (50 and $100 \mathrm{kGy}$ ), heat distortion occurs earlier and stronger. The temperature of the lower surface increases faster reaching high temperatures close to the temperature of the upper surface. Finally, the flame moves on the lower surface and covers the whole sheet. The measurements are stopped just before the falling of material through the central hole of the grid.

Comparing the temperatures of lower and upper surfaces for F5-4 blends allows assessing the temperature gradient into the material. Few seconds after ignition, before heat distortion, the temperature of the upper surface is already in the range $400-500{ }^{\circ} \mathrm{C}$ while the temperature of the lower surface is close to $150{ }^{\circ} \mathrm{C}$. A strong temperature gradient of $250-350{ }^{\circ} \mathrm{C}$ is the driven force leading to heat distortion of the radiation-crosslinked F5-4 blends.

\section{Conclusion}

In the best of our knowledge, the heat distortion of the specimen (due to the temperature gradient and the crosslinking of the polymer generated by the irradiation) and its effect on the flame retardancy has not been reported yet. This is quite surprising while this effect is not specific to PP/PA6 blends (we have qualitatively observed the same behavior for irradiated EVA materials). Many articles dealt with LOI to assess the flame retardancy. In this test, the temperature gradient is probably not high enough to generate heat distortion (the specimen is placed into the flame). Among the publications studying the flame retardancy of irradiated materials using cone calorimeter, only Liu et al. (2009)) quite enigmatically reported that "the irradiated ones (HDPE/EVA/magnesium hydroxide composites) behaved like an expanded bubble with a tendency for cracking in the middle, where the composites slowly burned".

Indeed, the effect of the heat distortion strongly depends on the mode-of-action of the flame retardant system. For pure PP/PA6 blends, heat distortion has no effect. Similarly, when the flame retardant does not act through an efficient barrier effect, few differences are observed between the unirradiated and irradiated materials. 
On the contrary, when barrier effect is involved, heat distortion disrupts the protective layer and leads to a dramatic increase of flammability. As seen in this study, the best flame retarded blend (F5-4) before irradiation can become the worst one after irradiation at high dose (at least in cone calorimeter with an irradiance of $35 \mathrm{~kW} / \mathrm{m}^{2}$ ).

Therefore, a guideline can be proposed to select a flame retardant system in polymers which are further radiationcrosslinked. Barrier effect should not be one of the main modeof-actions of the FR system. A challenging alternative is to develop FR systems which the barrier layer is flexible enough not to break under strain.

\section{Acknowledgements}

We thank Sylvain Buonomo and Alain Diaz for their help in preparing the formulations and specimens, and Sophie Rouif for $\gamma$-irradiation of the blends. We also acknowledge the support by the FUI VALEEE project.

\section{Appendix A. Supporting information}

Supplementary data associated with this article can be found in the online version at http://dx.doi.org/10.1016/j.radphyschem. 2014.08.012.

\section{References}

Ahmad, I., Shafiq, M., Yasin, T., 2013. Influence of gamma radiation on compatibilized LLDPE/magnesium hydroxide/sepiolite composites. J. Appl. Polym. Sci. 128 (3), 2236-2241.

Balabanovich, A.I., Levchik, S.V., Levchik, G.F., Schnabel, W., Wilkie, C.A., 1999. Thermal decomposition and combustion of $\gamma$-irradiated polyamide 6 containing phosphorus oxynitride or phospham. Polym. Degrad. Stab. 64, 191-195.

Balabanovich, A.I., Levchik, S.V., Levchik, G.F., Schnabel, W., 2001. Fire retardance in polyamide-6. The effects of red phosphorus and radiation-induced cross-links. Fire Mater. 25, 179-184.

Balabanovich, A.I., Schnabel, W., 2002. Fire retardance in polyamide-6,6. The effects of red phosphorus and radiation-induced cross-links. Macromol. Mater. Eng. 287 (3), 187-194.

Balabanovich, A.I., Zevaco, T.A., Schnabel, W., 2004. Fire retardance in poly(butylene terephtalate). The effects of red phosphorus and radiation-induced cross-links. Macromol. Mater. Eng. 289, 181-190.

Basfar, A.A., 2002. Flame retardancy of radiation cross-linked poly(vinyl chloride) (PVC) used as an insulating material for wire and cable. Polym. Degrad. Stab. 77, 221-226.

Basfar, A.A., 2003. Effect of various combinations of flame-retardant fillers on flammability of radiation cross-linked poly(vinyl chloride) (PVC). Polym. Degrad. Stab. 82, 333-340.

Bee, S.T., Hassan, A., Ratnam, C.T., Tee, T.T., Tin Sin, L., 2013. Investigation of nanosize montmorillonite on electron beam irradiated flame retardant polyethylene and ethylene vinyl acetate blends. Nucl. Instrum. Methods Phys. Res., Sect. B 299, 42-50.

Besson, J., 1998. Application of object-oriented programming techniques to the finite element method. Part II. Application to material behaviors. Eur. J. Finite Elem. 7, 567-588.

Coudreuse, A., Noireaux, P., Noblat, R., Basfar, A., 2010. Influence of radiation crosslinking and nano-filler on the flammability of ethylene vinyl acetate and low density polyethylene blends for wire and cable applications. J. Fire Sci. 28, 497-507.
Elton, S., 1998. Reduction of the thermoplastic melt hazard of polyester fabric through the application of a radiation cross-linking technique. Fire Mater. 22, 19-23.

Hagiwara, M., Sohara, M., Araki, K., Kagiya, T., 1980. Improvement of flameretardant properties of insulated wires by radiation crosslinking. J. Appl. Polym. Sci. 25, 1541-1547.

Huggett, C., 1980. Estimation of rate of heat release by means of oxygen consumption measurements. Fire Mater. 4 (2), 61-65.

Ismail, H., Munusamy, Y., Mariatti, M., Thevy Ratnam, C., 2010. The effect of trimethylol propane tetraacrylate (TMPTA) and organoclay loading on the properties of electron beam irradiated ethylene vinyl acetate (EVA)/natura rubber (SMR L)/organoclay nanocomposites. J. Appl. Polym. Sci. 117, 865-874.

Jia, S., Zhang, Z., Du, Z., Teng, R. Wang, Z., 2003. A study of the dynamic flammability of radiation cross-linked flame-retardant HDPE/EPDM/siliconelastomer compound. Radiat. Phys. Chem. 66, 349-355.

Jia, S., Zhang, Z., Wang, Z., Zhang, X., Du, Z., 2005. A study of $\gamma$-radiation-crosslinked HDPE/EPDM composites as flame retardants. Polym. Int. 54, 320-326.

Jiao, C., Wang, Z., Chen, X., Yu, B., Hu, Y., 2006. Irradiation crosslinking and halogenfree flame retardation of EVA using hydrotalcite and red phosphorus. Radiat. Phys. Chem. 75, 557-563.

Liu, H., Fang, Z., Peng, M., Shen, L., Wang, Y., 2009. The effects of irradiation crosslinking on the thermal degradation and flame-retardant properties of the HDPE/EVA/magnesium hydroxide composites. Radiat. Phys. Chem. 78, 922-926.

Lu, H., Hu, Y., Xiao, J., Kong, Q., Chen, Z., Fan, W., 2005. The influence of irradiation on morphology evolution and flammability properties of maleated polyethylene/clay nanocomposite. Mater. Lett. 59, 648-651.

Lugao, A.B., Artel, B.W.H., Yoshiga, A., Lima, L.F.C.P., Parra, D.F., Bueno, J.R., Liberman, S., Farrah, M., Tercariol, W.R., Otaguro, H., 2007. Production of high melt strength polypropylene by gamma irradiation. Radiat. Phys. Chem. 76, $1691-1695$.

Lyon, R.E., Walters, R.N., 2004. Pyrolysis combustion flow calorimetry. J. Anal. Appl Pyrolysis 71 (1), 27-46.

Pramanik, N.K., Haldar, R.S., Bhardwaj, Y.K., Sabharwal, S., Niyogi, U.K., Khandal, R. K., 2009. Radiation processing of Nylon 6 by e-beam for improved properties and performance. Radiat. Phys. Chem. 78, 199-205.

Quach, Y., Cinausero, N., Sonnier, R., Longuet, C., Lopez-Cuesta, J.M., 2012. Barrier effect of flame retardant systems in poly(methyl methacrylate): study of the efficiency of the surface treatment by octylsilane of silica nanoparticles in combination with phosphorous fire retardant additives. Fire Mater. 36 (7), 590-602.

Salem, E.F., Mostafa, N., Hassan, M.M., Mohsen, M., 2009. Effects induced by gamma irradiation on free-volumes, mechanical, and thermal properties of flame- and non flame-retardant polyvinylchloride. J. Appl. Polym. Sci. 113, 199-206.

Samyn, F., Bourbigot, S., Jama, C., Bellayer, S., 2008. Fire retardancy of polymer clay nanocomposites: is there an influence of the nanomorphology? Polym. Degrad. Stab. 93, 2019-2024.

Schartel, B., Hull, T.R., 2007. Development of fire-retarded materials-interpretation of cone calorimeter data. Fire Mater. 31, 327-354.

Schartel, B., Weib, A., 2010. Temperature inside burning polymer specimens: pyrolysis zone and shielding. Fire Mater. 34, 217-235.

Seo, D., Kim, J., Kang, P.H., Seo, C.E., Lee, J.H., Kim, H.J., 2012. Enhancement of flame retardancy and mechanical properties of HDPE/EPM based radiation shielding composites by electron beam irradiation. J. Nucl. Mater. 429, 99-104.

Senna, M.M.H., Abdel-Moneam, Y.K., Hussein, Y.A., Alarifi, A., 2012. Effects of electron beam irradiation on the structure-property behavior of blends based on low density polyethylene and styrene-ethylene-butylene-styrene-block copolymers. J. Appl. Polym. Sci. 125, 2384-2393.

Shafiq, M., Yasin, T., 2012. Effect of gamma irradiation on linear low density polyethylene/magnesium hydroxide/sepiolite composite. Radiat. Phys. Chem. $81,52-56$.

Shukri, T.M., Mosnacek, J., Basfar, A.A., Bahattab, M.A., Noireaux, P., Courdreuse, A., 2008. Flammability of blends of low-density polyethylene and ethylene vinyl acetate crosslinked by both dicumyl peroxide and ionizing radiation for wire and cable applications. J. Appl. Polym. Sci. 109, 167-173.

Wang, B., Wang, X. Shi, Y., Tang, G., Tang, Q., Song, L., Hu, Y., 2012. Effect of vinyl acetate content and electron beam irradiation on the flame retardancy, mechanical and thermal properties of intumescent flame retardant ethylenevinyl acetate copolymer. Radiat. Phys. Chem. 81, 308-315.

Zaidi, L, Bruzaud, S, Kaci, M., Bourmaud, A Gautier, N., Grohens, Y, 2013. The effects of gamma irradiation on the morphology and properties of polylactide Cloisite 30B nanocomposites. Polym. Degrad. Stab. 98, 348-355. 